\title{
Aeroelastic Stability of Labyrinth Seal with Different Structure Parameters
}

\author{
Wang Nengmao ${ }^{\mathrm{a}}$ and Wang Yanrong \\ Collaborative Innovation Center for Advanced Aero-Engine, School of Energy and power, Beihang University, 37 \\ Xueyuan Road, Haidian District,Beijing 100191, China
}

\begin{abstract}
Numerical analysis of turbomachinery based on energy method is used to predict the aeroelastic stability of the straight-through labyrinth seal by solving aerodynamic work and damping. The aeroelastic stability of the labyrinth seal under different working conditions and vibration modes has been compared. It's found that the increase of pressure ratio leads to the greater possibility of aeroelastic instability. The periodic distribution of the aerodynamic work in the circumferential direction of the labyrinth seal corresponds to the number of vibrating nodal diameters. In order to investigate the influence of structure parameters, the effect of relative thickness of the tooth tip, the width of the seal cavity and the eccentricity of the rotor on the aeroelastic stability of the labyrinth seal has been studied. The result of numerical calculation shows that the change of the structural parameters can affect the aeroelastic stability of the labyrinth seal to a certain extent, and can be applied in the structural optimization.
\end{abstract}

\section{Introduction}

Labyrinth seals are widely used to limit the fluid leakage in aeroengines. With the improvement of performance requirements, the flutter problem of labyrinth seal has become increasingly serious (Ehrich, F., 1968[1]). Alford [2] studied the phenomenon of self-excited vibration of labyrinth seal, and believed that friction between the seal components could introduce energy into the vibrating system, increasing amplitude and causing fatigue failure. The changes of gas pressure in seal cavity can also affect the vibration of the system. It was found that the support position at upstream or downstream of labyrinth seal can be selected to prevent self-excited vibration to a certain extent.

The problem of aeroelastic instability was investigated during the development of F100 engines (Lewis, Platt and Smith, [3]). Through extensive engine tests the instability was finally attributed to the tight clearance of the first (upstream) knife edge and could be eliminated by adjusting it. Abbott [4] showed that when the mechanical frequency is close to the acoustic frequency, the labyrinth seal will have the greatest aerodynamic instability. The aerodynamic damping is negative if the structural frequency is less than the acoustic frequency when the labyrinth seal is supported on the low pressure side. The aerodynamic damping is positive if the structural frequency is less than the acoustic frequency when the labyrinth seal is supported at the high pressure side.

Srinivasan [5] determined the relationship between the aerodynamic forces and the modes, frequencies and geometrical parameters by analyzing the vibration modes of the labyrinth seal. The

\footnotetext{
${ }^{\mathrm{a}}$ Corresponding author : wnm189981@163.com
} 
relationship between the aerodynamic forces and the geometrical parameters was determined by solving the characteristic equation. And the stability of the seal components can be determined by this method. It is believed that increasing the stiffness of the rotating and stator components and decreasing the circumferential velocity of the air flow can increase the stability of the labyrinth seal.

In view of the complexity of flutter prediction, the early flutter studies use an empirical method [6] and experimental method [1]. Amirante, Hills and Barnes [7] used the torsion spring model to perform the finite element analysis of the interstage cavity and the aerodynamic numerical calculation. The finite element analysis software can simulate many characters of the labyrinth seal and save a great deal of computation time and test cost.

In recent years, the numerical method and the basic theory of aeroelasticity of labyrinth seal are mainly derived from the method of predicting flutter of turbomachinery. The energy method proposed by Bendiksen [8] and Carta [9] to calculate the unsteady aerodynamic forces on the oscillating cascade and the work done on the blades in one oscillation period. The aerodynamic work is taken as the criterion for the system to produce flutter.

The energy method developed from flutter prediction of turbomachinery is applied by Sayma [10] to the flutter analysis of the air-riding seal. It is believed that the large axial and radial deformation, vibration of the seal, thermal expansion of the gas, unsteady turbulence, high-speed flow of the seal clearance and other factors led to the interaction of the seal aeroelastic and thermoelastic phenomenon. Phibel [11] showed that the ratio of the mechanical vibration frequency to the acoustic frequency and the support position of the seal have a great influence on the flutter stability. The distribution of aerodynamic work was relevant to the modal shape and the distribution of unsteady pressure.

Phibel [12] also compared the effects of the CFD program and the three-control model and the twocontrol model on the numerical results of the aeroelastic stability of the labyrinth seal. Mare [13] used the energy method to calculate the aeroelastic stability of labyrinth seal, and studied the difference of the aeroelastic stability with differentnumber of teeth.

In this paper, based on the mature computational fluid dynamics (CFD) and computational structural dynamics, a numerical method (Zhang [14]) of fluid-structure coupled vibration developed to predict the aeroelastic stability of turbomachinery blades has been applied to the labyrinth seal. Influence and sensitivity of seal parameters on aeroelastic stability of labyrinth seal are investigated.

\section{Numerical method}

\subsection{Fluid model}

The most commonly used equations for the computational fluid dynamics control equations involved in aeroelastic stability analysis are Navier-Stokes equations, which are developed from the three conservation laws of mass, momentum and energy. In a real flow problem, the flow state is mostly turbulence, and the flow is very irregular in time and space.

Because the gas density is far less than the density of the solid structure, the additional stiffness caused by the gas is far less than the stiffness of the structure, so the additional stiffness of the gas is neglected (Srinivasan [15]) as done in the vibration characteristic for the labyrinth seal. The mechanical damping is related to structural materials, structural forms and many other factors. It is generally believed that mechanical damping of turbomachinery is much less than that of aerodynamic damping [16]. Therefore mechanical damping is neglected and only the aerodynamic damping is taken into account. The mode shape and natural frequency of labyrinth seal are largely not influenced by unsteady aerodynamic loads.

In general, the structural grids are much sparser than the fluid-domain grids, and the two sets of meshes cannot be completely overlapped at their interface. Therefore, the vibration displacements of the structure element node need to be interpolated to the fluid domain grid point on the fluid-solid coupling interface after modal analysis. 


\subsection{Overview of Energy method}

In general, the mechanical damping of turbomachinery is far less than aerodynamic damping. Therefore, the influence of mechanical damping on aeroelastic stability is often neglected (Kielb and Imregun [16]) in the prediction of the aeroelastic stability of the labyrinth seal. The aerodynamic damping is used for judging whether flutter occurs in the labyrinth seal.

The excitation force (pressure) applied by the labyrinth seal to the flow field of the seal cavity is given by

$$
p=p(x, y, z, t)=p(x, y, z, t+T)
$$

The work of excitation force on the flow field in a vibration period

$$
W=\int_{0}^{T} \int_{S} p \vec{v} \cdot \vec{n} d S d t
$$

The natural frequency and mode shape of labyrinth seal in the flow field can be solved according to the modal analysis. Then unsteady flow field is analyzed by interpolating the vibrating displacement to the fluid grids as mesh deformation. Mesh deformation is an important component for solving problems with moving boundaries or moving subdomains. The motion of all remaining nodes is determined by the mesh motion model, which is currently limited to displacement diffusion. The displacements applied on domain boundaries or in subdomains are diffused to other mesh points. A transient periodic mesh motion is set that repeats itself at a given frequency.

The aerodynamic force and displacement of the coupled surface are used to calculate the aerodynamic work done by the airflow on the seal in a vibration period after the unsteady analysis, and then the aerodynamic damping is obtained.

The energy dissipated by the aerodynamic damping after the approximate treatment in a certain mode can be expressed as

$$
W_{\text {aero }}=\oint c_{\text {aero }} \dot{q} d q=2 \zeta_{\text {aero }} \omega \int_{0}^{T} \dot{q}^{2} d t=2 \pi \zeta_{\text {aero }} \omega^{2}\left(q^{\text {cfd }}\right)^{2}
$$

By the definition of equivalent viscous damping, there is

$$
\begin{gathered}
-W=W_{\text {aero }} \\
-W=2 \pi \zeta_{\text {aero }} \omega^{2}\left(q^{\mathrm{cfd}}\right)^{2}
\end{gathered}
$$

Therefore, the modal aerodynamic damping ratio can be expressed as

$$
\zeta_{\text {aero }}=\frac{-W}{2 \pi \omega^{2}\left(q^{\mathrm{cfd}}\right)^{2}}
$$

The modal aerodynamic damping ratio derived from the energy method is proportional to the unsteady aerodynamic work and is inversely proportional to the square of the amplitude and the natural frequency of labyrinth seal. That is, when the amplitude and the natural frequency are constant, the modal aerodynamic damping ratio would increase with the increase of aerodynamic work.

\section{Case study}

\subsection{Labyrinth seal geometry}

The aeroelastic stability of the labyrinth seal is predicted by the energy method. The structure of the model is shown in Figure1. The model is a four-tooth straight-through labyrinth seal consists of rotor and stator parts. The seal clearance is $0.5 \mathrm{~mm}$. It was pointed by Alford [2] that rotor seal had failed when supported at entrance side (high pressure side and upstream). So the boundary condition of supporting at entrance side was investigated. 


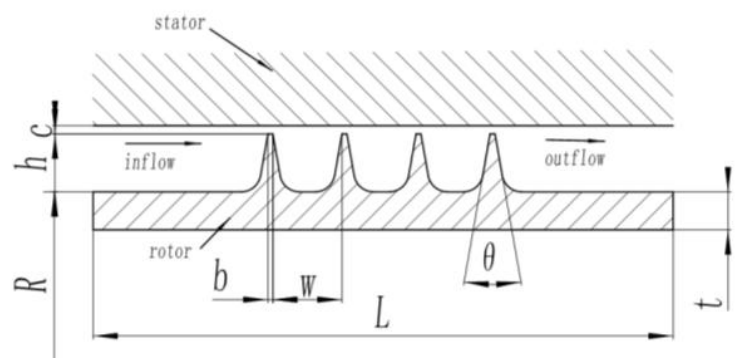

Figure 1. Labyrinth seal geometry.

\subsection{Modal analysis}

The following Figure 2(a) shows the finite element mesh model of the labyrinth seal for calculating the natural vibration characteristics. The number of nodes in the model is 70800 , and the grid is extruded to 120 layers in the circumferential direction. The labyrinth seal is supported at the inlet high-pressure side and its natural vibration characteristics under the rotating condition are calculated. For a short thin-walled cylinder structure, such as labyrinth seal, the main vibration displacement is at the radial direction. Figure 2(b) and 2(c) shows the 2 nodal diameters mode and 3 nodal diameters mode of the labyrinth seal. The maximum amplitude appears at the free side of the seal.

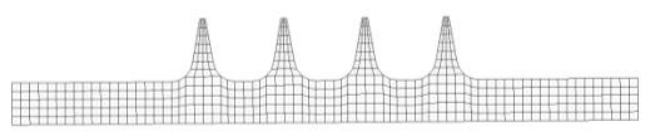

(a) Finite element model of the labyrinth seal
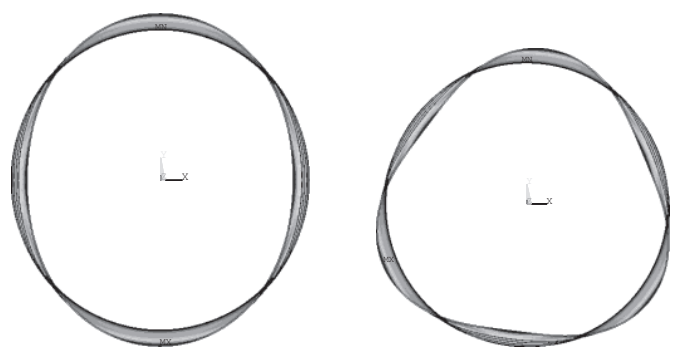

(b) 2 nodal diameters mode (c) 3 nodal diameters mode

Figure 2. Labyrinth seal FE model and 2 3 nodal diameters mode

The modal shapes of the labyrinth seal are obtained by finite element modal analysis, and the vibration displacement obtained by modal analysis can be interpolated to the fluid-structure coupling surface of the fluid domain by the developed data transfer algorithm. When the displacement interpolation is completed, the unsteady analysis of the cavity flow field is conducted by moving mesh technique under the displacement oscillation of the coupling surface. The steady-state analysis of the flow field is taken as the initial field of unsteady analysis to accelerate the convergence rate.

\subsection{Steady flow simulation}

The three-dimensional model is used to calculate the steady-state flow characteristics of the labyrinth seal cavity. In order to simulate the pressure ratio in this application, the fixed outlet pressure is set as the normal atmospheric pressure, and the total inlet pressure is adjusted for different pressure ratio from 1.2 to 3.6. The wall boundary is set to adiabatic and smooth. The ideal gas is selected as working fluid. 
Figure3 lists Mach number and total pressure contour of the labyrinth seal. There are obvious stratification phenomena in the process of airflow passing through the teeth of each cavity. The upper part is the jet area and the lower part is the turbulence area. When the airflow is blocked by the tooth surface, a whirlpool is formed in the tooth cavity. The Mach number of the vortex flow close to the seal surface is higher and the Mach number of cavity center is the smallest. During the process of airflow passing through each seal, the pressure decreases gradually, and the pressure drop of the airflow through the first tooth is the largest.

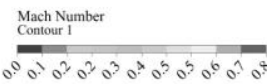

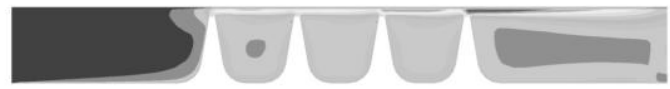

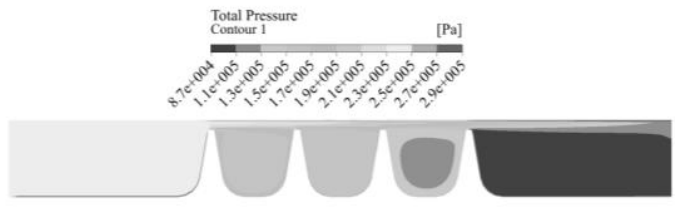

Figure 3. Predicted Mach number and total pressure contour at pressure ratio $=2.4$

\subsection{Results and Discussions of Energy Method}

The unsteady flow analysis is carried out by setting the labyrinth seal to vibrate with specified frequency and mode shape. The results of steady flow analysis are taken as initial conditions. The coordinates of the mesh nodes at the specified coupling surface of the flow field are set to oscillate with the law of sinusoidal motion.

The unsteady aerodynamic force and the displacement at each time step of the coupling surface in the flow field are derived for data post processing. And then the unsteady aerodynamic work and modal aerodynamic damping ratio in one vibration period are calculated. Figure 4 shows the aerodynamic work and modal aerodynamic damping ratios for $3 \sim 6$ nodal diameters mode shape. By the definition of the energy method, negative aerodynamic work in a cycle indicates that the energy of labyrinth seal continuously release into the gas and the structure is stable.

Correspondingly, the positive modal aerodynamic damping ratio and negative aerodynamic work indicates that the aerodynamic damping of the labyrinth seal is consuming energy. It can be seen from Figure 4 that the aerodynamic work of the labyrinth seal changes almost lineally with the pressure ratio under different nodal diameter modes. When the pressure ratio is relatively small, the aerodynamic work is negative and the structure is stable. When the pressure ratio increases to a certain extent, the aerodynamic work will change from a negative value to a positive value and the structure becomes unstable. The aeroelastic stability of the labyrinth seal varies with the operating conditions. There are some differences in aeroelastic stability under different vibration modes. It can be seen that the 3 nodal diameters mode has better stability and the 5 nodal diameters mode is more prone to aeroelastic instability.

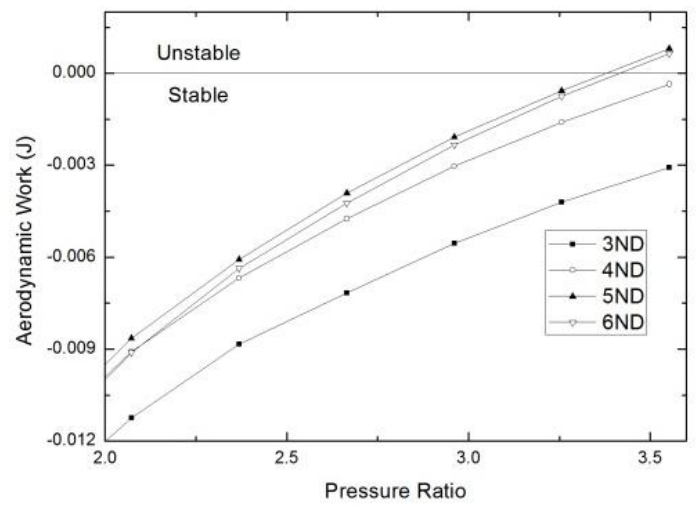

(a) Aerodynamic work of the labyrinth seal

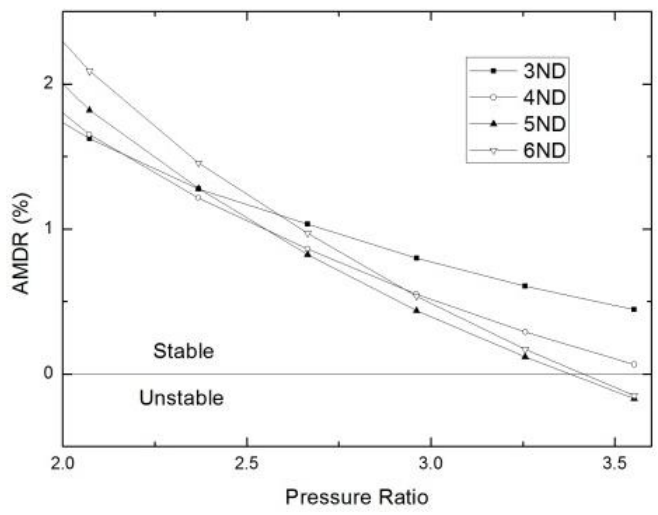

(b) Modal aerodynamic damping ratio

Figure 4. Aerodynamic work and AMDR of $3 \sim 6$ nodal diameters at different pressure ratio. 


\section{Conclusion}

In this paper, the aeroelastic stability of the labyrinth seal is predicted by the energy method. The influence on the aeroelastic stability of the labyrinth seal under different working conditions and vibration modes is investigated. The effects of the relative thickness of the tooth tip, the width of the seal cavity and the eccentricity of the rotor on the aeroelastic stability of the labyrinth seal are also studied. The conclusions are as follows:

The weak coupling calculation method based on energy method can analyze the solid domain and the fluid domain model separately, and transfer the displacement through linear interpolation, so that the calculation is simplified greatly. The vibration characteristic of labyrinth seal is similar to the short cylindrical shell that the radial displacement plays a major role. When supported at entrance side (high pressure side or upstream), the largest radial displacement is at the discharge side. However, the pressure at entrance side is higher. The aeroelastic stability of labyrinth seal can be solved at different natural frequency and working conditions. When the pressure ratio of the model increases, the area of the positive aerodynamic work of the coupling surface enlarges, resulting in the decrease of the aerodynamic damping ratio.

\section{References}

1. F. Ehrich, Aeroelastic Instability in Labyrinth seals, ASME Paper, No. 68-GT-32, (1968)

2. J. S. Alford, Protection of Labyrinth Seals From Flexural Vibration, ASME J. Eng. Power, 86, (1964)

3. D. A. Lewis, C. E. Platt, B. E. Smith, Aeroelastic Instability in F100 Labyrinth Air Seal, AIAA J. Aircraft, 16, (1979)

4. D. R. Abbott, Advances in Labyrinth Seal Aeroelastic Instability Prediction and Prevention, ASME Paper, No. 80-GT-151, (1980)

5. A. V. Srinivasan, Aeroelastic Instabilities in Labyrinth Air Seal Systems, ASME Paper, No. 84GT-169, (1984)

6. J. S. Alford, Nature, Causes, and Prevention of Labyrinth Air Seal Failures, AIAA J. Aircraft, 12, (1975)

7. D. Amirante, N. J. Hills, Barnes, Thermo-Mechanical Finite Element Analysis/Computational Fluid Dynamics Coupling of an Interstage Seal Cavity Using Torsional Spring Analogy, ASME J. Turbomachinery, 134, (2012)

8. O. O. Bendiksen, Aeroelastic Problems In Turbomachines, AIAA Paper, No. 90-1157, (1990)

9. F. O. Carta, Coupled Blade-Disk-Shroud Flutter Instabilities in Turbojet Engine Rotors, ASME J. Eng. Power, 89, (1967)

10. A.I. Sayma, C. Breard, M. Vahdati, M. Imregun, Aeroelasticity Analysis of Air-Riding Seals for Aero-engine Applications, ASME J. Tribology, 124, (2002)

11. R. Phibel, L. D. Mare, J. S. Green, M. Imregun, Numerical Investigation of Labyrinth Seal Aeroelastic Stability, ASME Paper, No. GT2009-60017, (2009)

12. R. Phibel, L. D. Mare, Comparison Between a CFD Code and a Three-Control-Volume Model For Labyrinth Seal Flutter Predictions, ASME Turbo Expo, No. GT2011-46281, (2011)

13. L. D. Mare, M. Imregun, J. S. Green, A. I. Sayma, A Numerical Study of Labyrinth Seal Flutter, ASME J. Tribology, 132, (2010)

14. Zhang, X. W., Wang, Y. R., and Xu K. N., Flutter Prediction in Turbomachinery with Energy Method, Proc. Inst. Mech. Engi., Part G: J Aero Eng, 225, (2011)

15. A. V. Srinivasan, Flutter and Resonant Vibration Characteristics of Engine Blades, ASME Paper, No. 97-GT-533, (1997)

16. R. E. Kielb, M. Imregun, Aeroelasticity in Axial Flow Turbomachines, NASA, No. TP-2006212490, (2006) 